\title{
A revolução Tunisiana e a dialética entre teatro e realidade ${ }^{1}$
}

\section{The Tunisian Revolution and the Dialectics of Theatre and Reality}

Marvin Carlson ${ }^{2}$

Tradução: Vívian de Camargo Coronato ${ }^{3} e$ Glória Paschoal de Camargo ${ }^{4}$ 


\section{Resumo}

O entrelaçamento entre teatro é realidade é quase sempre uma importante parte da dinâmica da revolução e, sem dúvida, pode ser observado na Revolução Tunisiana de 2011, que deu início à "Primavera Árabe". Este artigo irá considerar três exemplos significantes desse processo, envolvendo duas peças recentes Khamsūn (Cinquenta, escrita em 2006) e Yahia Yaïsh (Amnésia, escrita em 2010), criadas por dois dos principais artistas teatrais da Tunísia, a dramaturga Jalila Baccar e seu diretor/marido Fadhel Jaïbi, e $o$ ato (performance da vida real) do tunisiano Abd-En-Nasser Laouini que, ao comemorar nas ruas quase desertas devido ao toque de recolher, a fuga do ditador Ben Ali, acabou por realizar uma performance teatral, que foi filmada sem seu conhecimento e rapidamente alcançou as redes sociais e os canais de televisão.

Palavras-chave: Tunísia, teatro, revolução, arte-vida

\section{Abstract}

The intermingling of theatre and reality is usually an important part of the dynamics of revolution, and was certainly to be seen in the 2011Tunisian Revolution, which initiated the so-called "Arab Spring." This paper will consider three significant examples of this process, involving two recent plays, Khamsūn (Fifty, written in 2006), and Yahia Yaïs (Amnesia, written in 2010) created by two of Tunisia's leading theatre artists, the playwright Jalila Baccar and her director/ husband Fadhel Jaïbi, and the real-life performance of Abd-En-Nasser Laouini that expressed his jubilation due the fled of the dictator Ben Ali, in the almost deserted streets, due to a night time curfew, turned out to a theatrical performance, which was filmed, without his knowledge of it, and quickly reached the social networks and TV channels.

Keywords: Tunisia, revolution, theatre, art-life

\footnotetext{
${ }^{1}$ Todas as citações foram traduzidas ao português a partir de traduções de textos em francês e em árabe realizadas pelo próprio Marvin Carlson.

${ }^{2}$ Professor Doutor de Teatro e Literatura Comparada no Centro de Graduação da Universidade da Cidade de Nova lorque (Estados Unidos).

${ }^{3}$ Doutoranda do Programa de Pós-Graduação em Teatro (PPGT) da UDESC.

viviancoronato@gmail.com

${ }^{4}$ Professora Mestre do curso de Curso de Automação de Escritórios e Secretariado da Faculdade Tecnológica de São Paulo (FATEC-SP).
} 
O entrelaçamento entre teatro é realidade é quase sempre uma importante parte da dinâmica da revolução e, sem dúvida, pode ser observado na Revolução Tunisiana de 2011, que deu inicio à "Primavera Árabe". Este artigo irá considerar três exemplos significantes desse processo, envolvendo duas peças recentes e um ato (real-life performance) que foi teatralizado. As duas peças foram criadas por dois dos principais artistas teatrais da Tunísia, a dramaturga Jalila Baccar e seu diretor/marido Fadhel Jaïbi. As dua speças são Khamsūn (Cinquenta, escrita em 2006) e Yahia Yaïsh (Amnésia, escrita em 2010). Khamsūn é particulamente significativa na sua confrontação com as práticas repressivas do governo pré-revolucionário. Durante os cinquenta anos passados da Independência, de 1956 a 2006, o sistema politico tunisiano foi dominado por um único partido, e qualquer um que se opusesse ao regime corria um grande risco. Mas Khamsūn e Yahia Yaïsh sugerem que a repressão política poderia levar, entre outras coisas, ao terrorismo islâmico, como exempificado em Khamsūn, e à subsequente queda do governo tunisiano, como apresentado em Yahia Yaïsh. Diferentemente do governo tunisiano, que tem uma visão simplista do terrorismo islâmico, Khamsūn mostra como esta questão é mais complexa. Ao exercer repressão sob o pretexto de proteger o povo tunisiano do terrorismo, o governo estabeleceu as condições que levaram à sua própria queda - um evento que Yahia Yaïsh representa e que prevê, acertadamente, que iria ocorrer em breve. A violação dos direitos humanos é central nessa política de repressão, manifestada através do encarceramento, da prisão e do silenciamento daqueles que denunciaram o repressivo governo tunisiano e suas instituições incompetentes. Em seu Goulag \& Démocratie, Mohamed Talbi ${ }^{6}$ apresenta inúmeros exemplos de violações de direitos humanos na Tunisia. Por exemplo, Talbi menciona Sihem Bensedrine, uma tunisiana jornalista e ativista dos direitos humanos, que teve seu "passaporte [...] confiscado, [...] foi presa, [e] submetida a brutais agressões físicas pela polícia tunisiana" (Talbi, 2011, p.11). Bensedrine foi perseguida por condenar os abusos do govenro tunisiano, como tortura, falta de liberdade de expressão, e a ausência de um judiciario independente. Além de Talbi, Robin Wright, um prolífico correspondente estrangeiro, também descreve como a Revolução Tunisiana demonstrou o ódio contra o autoritarismo do estado tunisiano. Em seu trabalho, Rock the Casbah: Rage and Rebellion Across the Islamic World (2011) ${ }^{7}$, Wright explica que antes da Revolução Tunisiana o governo controlava todas as instiuições, incluindo a mídia, finanças e transportes.

O teatro em particular sofreu com esse controle repressivo e Khamsūn nos dá um exemplo importante e revelador disso. Embora a peça tenha sido comissionada pelo governo para ser apresentada no Teatro Nacional como parte das celebrações do quinquagésimo aniversário da independência, seu retrato negativo de determinadas figuras políticas tunisianas e sua visão simpática ao fundamentalismo islâmico foi alvo de censura e, em seguida, de proibição. A peça não apenas ousava representar o terrorismo islâmico no palco, como também a forma com que ideologia oficial

\footnotetext{
${ }^{5}$ Cujo elenco era formado por: Fatma Ben Saîdane, Sabah Bouzouita, Ramzi Azaiez, Moez M'rabet, Lobna M'lika, Basma El Euchi, Karim El Kefi, Riadh El Hamdi, Khaled Bouzid e Mohammed Ali Kalaî

${ }^{6}$ Talbi é um historiador tunisiano que publicou em 2011 Goulag \& Democratie. Nesse trabalho ele menciona que nenhuma editora na Tunísia, França ou Marrocos aceitou a publicação do livro antes da queda do regime tunisiano. No final, ele mesmo publicou seu próprio livro. (N.A.)

${ }^{7} \mathrm{O}$ autor não indica o livro nas referências ou nas notas.
} 
vinha tentando erradicá-lo. Essa consistia em condenar qualquer tunisiano considerado como potencial terrorista islâmico ou qualquer pessoa que parecesse possuir uma conexão, por mais sutil que fosse, com os islâmicos. Além disso, o regime não fazia distinção entre políticos islâmicos e pessoas espiritualizadas, como, por exemplo, quem frequentava mesquitas ou vestia véu como parte de sua rotina cotidiana e código de vestimenta.

Banida na Tunísia, a peça teve sua première mundial em 2006, no Teatro Nacional Francês, o Odéon, em Paris, sendo tão bem recebida que o governo tunisiano voltou atrás e permitiu que fosse apresentada na Tunísia no ano seguinte. Ali, de acordo com a jornalista Zoé Lamazou, a produção abriu espaço para reflexão e a expressão. Lamazou (2007, p. 93) aponta que a peça "encheu o auditório" com um público curioso para ver um trabalho que lidava com o terrorismo islâmico, ousando romper o silêncio do governo sobre o tema. A peça também sugere que o regime repressivo também levou, entre outras coisas, ao empobrecimento da mídia, abafando uma grande variedade de expressões intelectuais e artísticas.

Khamsūn conta sobre os eventos ocorridos depois que Juda, uma professora de ensino médio que se temia ser uma terrorista islâmica, suicidou-se com uma bomba próxima à bandeira da Tunísia, fato que provocou temor no pais inteiro. Baccar sugere em Khamsūn uma conexão entre a revolta da juventude escolarizada tunisiana e a opressão da arcaica estrutura política tunisiana. Investigando a morte de Juda, o departamento de polícia interroga aqueles que tiveram ligações com ela antes de seu suicídio. Duas jovens de véu, Amal e Hanen, e Ahmed, um aluno de Juda, todos são suspeitos de serem cúmplices do suicídio de Juda. Khamsūn é centrada na suspeita oficial de que todos as pessoas próximas a Juda são fundamentalistas islâmicos e, portanto, carregam a semente terrorista. A história dessas personagens representa o conflito ideológico de forças na sociedade tunisiana, que inclui, entre outros, Sufismo (islã místico), pan-islamismo e o terrorismo islâmico. Khamsūn levanta questões sobre a preocupação nacional com os homens-bomba e o seu impacto na imagem da Tunísia, de fato um dos países mais seguros da região. A polícia quer saber porque alguém como Juda pode cometer um atentado suicida após orar na escola perto da bandeira tunisiana.

O corpo destroçado de Juda é refletido na bandeira danificada, tornando a crítica política mais explicita. Em 2012, contemplando Khamsūn em retrospectiva, Khalid Amine e Marvin Carlson ${ }^{8}$, dois proeminentes críticos teatrais, apontam que Khamsūn levanta a seguinte questão "se chegou-se a um beco sem saída ou, talvez, a uma pausa final antes de um novo começo?" (Amine; Carlson, 2012, p.212). Não é de surpreender que o suicídio de Juda perto da bandeira da Tunísia pudesse levantar tal questão alarmante, avisando ao público o desastre que estaria por vir. O título, que significa "cinquenta" em árabe, sugere o perigo da longevidade de um governo, refletido na incompetência crescente nesses cinquenta anos no poder. Ao escolher esse título, Baccar, ironicamente, parece celebrar o dia do quinquagésimo aniversário da Independência Tunisiana com Juda cometendo seu atentado suicida perto da ban-

${ }^{8}$ Observar que Carlson é o autor do artigo e que aqui se refere na terceira pessoa. (N.T.) 
deira da Tunísia.

A peça também critica o arcaico sistema policial através de Gaddour (Jamel Madani), o torturador. O sistema, nesses cinquenta anos, não mudou suas práticas, incluindo, notoriamente, sua tradição de tortura. Gaddour assegura a estrutura política oficial mantendo o controle e a conformidade através do uso da força e da humilhação. Ele tem um papel central na peça, pois ele não é apenas a força motriz da ação cênica, mas conecta a velha e a nova geração, aqueles que foram oprimidos por um curto período e aqueles que foram subjugados por um longo tempo. O próprio torturador é ele mesmo controlado não parece capaz de questionar o monótono funcionamento despótico do sistema policial. Por exemplo, no terceiro ato da seção três, Maryam - a mãe de Amal (interpretada por Jalila Baccar) - repetidamente relembra Gaddour de quando ele torturava seu marido Youssef (Moez Mrabet) e que ela estava sendo interrogada pela quarta vez.

Ao oferecer diferentes perspectivas do termo "fundamentalismo", Baccar desafia a visão reducionista política tunisiana estabelecida e oferece outras possibilidades de interpretação do que o fundamentalismo islâmico poderia significar e as razões pelas quais ele poderia se espalhar, especialmente entre a escolarizada juventude da Tunísia pós-colonial. A esse respeito, o suicídio de Juda serve de crítica ao governo tunisiano pelo possível papel que desempenhou ao tentar erradicar o fundamentalismo islâmico e proteger as pessoas às custas de seus direitos fundamentais, como liberdade de expressão, liberdade de afiliação política e liberdade de prática religiosa. Na realidade, Khamsūn sugere, subversivamente, que outra faceta do terrorismo foi perpetuada durante os cinquenta anos de opressão política na Tunísia, em que o próprio governo tomou medidas extremas contra os cidadãos. Além do mais, diferentemente do sistema policial repressivo tunisiano que, por exemplo, equivale o uso do véu a um extremismo religioso, Baccar aponta que o fundamentalismo islâmico é multifacetado e não pode ser reduzido a uma simples questão como a do uso de certas vestimentas.

Embora pouca coisa seja dita sobre o pupilo de Juda, Ahmed, a força policial está aparentemente certa em considerá-lo terrorista porque ele confessou ter colaborado com Juda, seguindo sua convicção. É possível, no entanto, considerar o comportamento de Ahmed como uma reação ao regime repressivo. O retrato de Ahmed é fascinante porque Baccar joga entre ficção e realidade através do uso de expressões que podem ser combinadas com certos eventos que refletem a situação política na Tunísia. Por exemplo, a dramaturga escolhe o 15 de novembro de 1987 como a data de nascimento de Ahmed, o que insinua que o governo tunisiano de 1987 (Ben Ali esteve no poder entre 07 de novembro e 14 de janeiro de 2011) seja o alvo da crítica. Esta data sugere que foi este governo que produziu terroristas, como Ahmed e Juda, enquanto se preocupava em eliminar brutalmente, através de todas formas possíveis, os movimentos islâmicos da cena política. Parece que a peça vai além de apenas condenar o terrorismo, ao convidar o leitor a explorar como ambos, Ahmed e Juda, como forma de resistência contra o repressivo governo Tunisiano de 1987, foram levados a um discurso religioso fanatista.

As histórias dos três personagens suspeitos de serem cúmplices do suicídio de Juda são todas diferentes: Amal, Hanen, e Ahmad, cada um representa um conflito 
de forças ideológicas na sociedade tunisiana. Contudo, a história de Amal é mais ambígua que as outras e, por isso, merece maior consideração. A forma como Baccar constrói a personagem de Amal sugere uma diferente forma de resistência ao regime político tunisiano, o que complica qualquer interpretação simplória do véu como um ícone político. Por exemplo, quando retorna para Tunísia, Amal é presa porque fora colega de quarto de Juda. Amal também foi presa por usar o véu, especialmente depois que se soube que um antigo namorado dela fora identificado como suspeito de ser terrorista na França. Ironicamente, foi nos seculares círculos parisienses que Amal decidiu abandonar seus pais, seus valores de esquerda, usar o véu e se tornar uma mulçumana sufi. Na segunda parte de Khamsūn, Amal envia um e-mail a seus pais informando-os do caminho espiritual escolhido e como ela situa o sufismo islâmico no centro de sua vida: "Mãe, pai, eu sou uma devota e cada gota do meu sangue volta-se para adorar Allah" (Baccar, 2007, p 75). Convertida ao sufismo, Amal é considerada diferente, mas aceita no meio social francês, enquanto é desprezada no meio social tunisiano. Ela é rejeitada pelo pai Youssef, e rotulada pela polícia tunisiana como fundamentalista islâmica.

A representação de Amal como uma mulçumana sufi parece ser incompatível com o fato de que ela seja atraída pelo islã político baseado em seu relacionamento com Juda ou com seu antigo namorado. Ainda assim, o que o texto escrito de Khamsūn falha em expressar é a importância do significado da coreografia na performance, que é o que levanta a questão. Os rodopios e súplicas de Amal no palco, por exemplo, contém pistas preciosas sobre ela ser uma sufi, e não uma fundamentalista. No entanto, apesar da dança sufi no palco, surpreendentemente tanto a mídia francesa quanto a tunisiana interpretaram, da mesma maneira, que Amal seria uma seguidora do fundamentalismo islâmico. É importante resistir às suposições que associam o uso do véu, ou uma mulher sufi, ao fundamentalismo islâmico. Assim como o ato de Juda, a mudança ideológica de Amal é reduzida pelo regime político tunisiano como uma simples e certeira indicação de fundamentalismo islâmico.

A recepção de Khamsūn na França mostra como essa ênfase no radicalismo islâmico foi ali também perpetuada, como poder ser visto na brochura do Odeon que publicitava a performance em 2006. Amal foi também retratada como mulçumana radical nos jornais e revistas francesas. No Liberation, a jornalista Maïa Bouteillet (2007, p.26) escreveu "Amal, uma jovem de uma família saudável que teve uma educação secular foi recentemente levada ao fundamentalismo. Ela foi presa no dia posterior ao atentado suicida cometido por uma de suas amigas". Ver Amal como uma mulçumana radical mostra o poder do discurso que opera amplamente não apenas na França como também na Tunísia (assim como em outras partes do mundo). Há pouquíssimas evidências que sugerem que o uso do véu por Amal deva ser visto pelo público da mesma maneira que as autoridades o veem na peça: como uma indicação de sua associação ao fundamentalismo islâmico.

É importante notar que a força policial e Maryam diferem em suas tentativas de lidar com o fundamentalismo islâmico. Baccar argumenta que na Tunísia não há espaço para qualquer prática diferente das ditadas pelo regime oficial. Para esse regime, silenciar a quem se pensa ter uma posição extremista, como o fundamentalismo islâmico, é a melhor forma de evitar uma séria crise política. Diferentemente das 
autoridades, Maryam tenta contextualizar politicamente o ato de Juda e a mudança ideológica de Amal, considerando os eventos dos últimos cinquenta anos. A preocupação de Maryam com as causas do terrorismo a leva para uma exploração do conflito que emerge da relação entre a determinação do governo tunisiano de erradicar tanto o terrorismo como o uso do véu pelas mulheres.

Depois da revolução tunisiana, Khamsūn pode ser interpretada como profética, ao compararmos suas principais preocupações com as da revolução tunisiana e suas consequências. Assim, a preocupação de Khamsūn com o fundamentalismo islâmico entre jovens desesperados como Juda e Ahmed pode ser comparada com o protesto político extremo que ocorreu após Mohamed Bouazizi ter se auto imolado em 17 de dezembro de 2011. Ahmed, Juda e Bouazizi estão envolvidos em atos parecidos de suicídios ou atentados suicidas como forma de protesto ao governo tunisiano. Ahmed especificamente justifica seu atentado suicida como maneira de expressar sua luta contra os líderes injustos de seu país, contra as injustiças cometidas em outros países como Palestina, Iraque e Afeganistão (Baccar, 2007, p.186). O ato suicida de Bouazizi também foi uma maneira de reagir contra o governo municipal, que confiscara seu carrinho de frutas, seu único meio de sobrevivência. A diferença entre os dois principais suicidas, no entanto, reside no fato de que a morte de Juda na peça nos leva a observar como o regime tunisiano acusa todos os conhecidos de Juda sem fazer qualquer esforço por explorar a complexidade do fundamentalismo islâmico. A autoimolação de Bouazizi, por outro lado, incitou manifestações contra o presidente e seu regime que se espalharam por toda Tunísia, resultando na revolução tunisiana, a renúncia do presidente e a queda do sistema policial tunisiano.

É preciso dizer que o temor de Khamsūn com relação ao fundamentalismo islâmico não foi descabido. Com efeito, após a Revolução, um movimento salafista emergiu alinhado com a ascensão de novos movimentos políticos que não estiveram presentes durante os últimos sessenta anos da história tunisiana. De acordo com Talbi (2011, p. 7), “o Islã Salafista é de um totalitarismo obscuro do pior tipo, pior que todas as ditaduras. Pense no Taliban! ". Talbi considera o movimento salafista como uma forma de ditadura, pelo fato de ser baseado em um conjunto estrito de regras que aderem a interpretações ortodoxas das leis islâmicas. Os salafistas estão em guerra contra quem não acredita em suas interpretações próprias do Islã. Alguns salafistas inclusive acreditam na jihad, que literalmente significa guerra. A crença na jihad os encoraja a sacrificar-se contra seus inimigos. Essa ideologia sustenta que todos aqueles que não são mulçumanos, ou aqueles que desviam do que os salafistas entendem por islã, estão sujeitos a punições, incluindo a morte. Deve ser dito, no entanto, que, conforme aponta Jorshi (2011), a maioria dos salafistas não são violentos ou politicamente engajados.

Apesar de apenas uma minoria dos grupos salafistas serem terroristas, parece razoável alegar que Khamsūn lida, em parte, com o crescimento do movimento salafista porque a peça discute o conceito global de fundamentalismo islâmico em relação a um tipo especifico de terrorismo associado aos salafistas, os atentados suicidas. A peça permanece, no entanto, mais preocupada com os efeitos corrosivos, incluindo o terrorismo, de viver sobre uma longa ditadura. Infelizmente, grupos extremistas nascidos sob estas condições geralmente, por sua vez, tornam-se tam- 
bém ditatoriais. Atualmente os grupos salafistas representam uma ameaça aos não -mulçumanos, artistas, advogados, mulheres e outros. Por exemplo, em novembro de 2011, estudantes salafistas foram capazes de atrasar os exames na Universidade de Manouba, a Faculdade de Letras, Artes e Humanidades em Tunis. Ao protestarem ficando sentados no meio do caminho, os salafistas impediram que milhares de estudantes realizassem seus exames, sob o pretexto de que deveria ser permitido em qualquer ocasião o uso da burca (o véu que cobre todo o rosto com exceção aos olhos; às vezes esse véu possui uma rede que acaba encobrindo, também, os olhos) por estudantes salafistas.

Suzanne Daley (2012, p.4), correspondente estrangeira do New York Times afirma "Aqui um punhado de salafistas ultraconservadores e seus ônibus cheios de adeptos, muitos dos quais vindos do interior pobre do país, se colocam contra uma faculdade urbana [Manouba] com o forte sentimento de que este esqueleto de campus, com seus caminhos tomados pelo mato, não é lugar para orações ou para mulheres que usam véu em suas faces. ". A reportagem de Daley mostra que depois da revolução ocorrida na Tunísia, a cena política sofreu mudanças ao incorporar as pluralidades, permitindo, assim, espaço para os salafistas, um grupo de pessoas que incluem uma minoria islâmica extremista, atuarem. Claro, o perigo está na inabilidade do atual governo de lidar com grupos extremistas como os salafistas, que perturbam a ordem social para atender a seus propósitos ideológicos.

A próxima produção de Baccar e Jaïbi, Yahia Yaïsh (Amnésia) de 2010, forneceu um exemplo notável da estreita relação entre teatro e realidade. Esse trabalho foi memoravelmente profético em relação aos acontecimentos revolucionários ocorridos no ano seguinte, a renúncia de Ben Ali e o colapso de seu regime em 2011. Desde o início, Yahia Yaïsh anuncia uma mudança de poder: Yahia (Ramzi Azaiez), o primeiro ministro, é zombado em uma transmissão televisiva no dia de seu aniversário, e é anunciada a sua demissão devido a abuso de poder. Seguindo com as notícias, Yahia é acusado de queimar sua própria biblioteca durante sua prisão domiciliar. Como resultado, ele é condenado a uma instituição psiquiátrica. A paralisia de Yahia é uma analogia para sua desgraça, que se inicia quando ele perde o poder. A condição de paralisia e de doença mental de Yahia destaca-se como uma metáfora para o doente regime político tunisiano. Na verdade, talvez uma premonição da queda do regime de Ben Ali possa especificamente ser vista na representação do corpo de Yahia se desintegrando ao final da performance. Yahia descreve a si mesmo dessa maneira: "Um corpo/ Uma cabeça/ Completamente desmembrado/ Disperso/ Jogado aos quatro ventos" (Baccar e Jaïbi, 2010). Em seu monólogo dramático Baccar e Jaïbi apresentam um indivíduo derrotado e, extensivamente, um estado coletivo derrotado que sinaliza o fim do regime político de Ben Ali em seu país.

Ao comparar rapidamente Khamsūn a Yahia Yaïsh, é possível observar uma mudança radical no que diz respeito à relação entre o teatro de Jaïbi e a realidade política tunisiana. Por exemplo, a repressão e a tortura são apontadas de maneira mais direta em Khamsūn que em Yahia Yaïsh. Como consequência, ao invés da direta desaprovação oficial de Khamsūn no comitê de censura, Yahia Yaïsh não foi censurada. Ao invés disso, a peça foi objeto de apenas algumas pequenas alterações, como admitiu o diretor teatral e dramaturgo em uma entrevista a dois repórteres radialistas france- 
ses, Caroline Broué e Hervé Gardette (Baccar e Jaïbi, 2011). Nessa entrevista, Baccar assinala que embora Yahia Yaïsh não tenha sido censurada, o Comitê de Orientação Teatral (a Censura) deteve a peça por dois meses. Baccar também declarou que após uma discussão com o ministro da cultura "algumas alterações" foram efetuadas. Em seu artigo sobre Yahia Yaïsh, Odile Quirot (2011, p.80), um jornalista e crítico de teatro do Nouvel Observateur, também observa: "Sob o regime de Ben Ali, Fadhel Jaïbi foi claramente obrigado a contornar a censura". Com essa declaração Quirot usa Yahia Yaïsh para demonstrar como é possível criticar de maneira velada o regime tunisiano. Ao encenar Yahia Yaïsh como uma metáfora estendida, Jaïbi e Baccar escaparam dos limites da censura e puderam, assim, ridiculizar os detentores do poder na Tunísia pós-colonial. Amine e Carlson (2012, p.213) argumentam: “Esta produção de 2010 é um chamado para que os detentores do poder revejam as suas relações com os cidadãos". Sensibilizar os detentores de poder a reconsiderar sua relação com a sociedade foi, na verdade, um dos maiores objetivos do teatro de Jaïbi. Alertando que o poder poderia não durar para sempre, que o resultado da opressão poderia levar à fuga do país para escapar da justiça, e da subsequente queda do regime - o que torna a performance a mais visionária da produção de Jaïbi e Baccar.

Quando Yahia está para ser levado à justiça, ele foge da instituição psiquiátrica e vai para o exterior, em um dos eventos mais surpreendentes de Yahia Yaïsh pois antecipa o voo do presidente da Tunísia deposto, Ben Ali, com alguns membros de sua família à Arábia Saudita. Embora esta alegoria seja comum em narrativas, que significa a morte ou o fim da ditadura, é razoável alegar que Yahia Yaïsh é diferente. Essa performance não apenas aponta a queda e o voo de Ben Ali, mas ocorre concorrentemente com a Revolução, pois a performance foi apresentada continuamente desde 2010, durante mais de um ano. A inter-relação entre os eventos da peça e os eventos ocorrido na Revolução Tunisiana podem ser observada em tantos detalhes que resultam em uma convergência entre ficção e realidade.

Yahia e Ben Ali têm muitas coisas em comum. Ambos abusaram de seu poder, o que levou, nos dois casos, a um voo para fora do país com muitos de seus familiares. Durante a Revolução Tunisiana, outro exemplo da sobreposição entre teatro e vida real culmina com a música tocando dentro do teatro municipal em Tunis durante a abertura de Yahia Yaïsh, enquanto a polícia usava gás lacrimogêneo fora do teatro, a fim de controlar a multidão protestando. A música da peça, escrita por Gérard Hourbette, contém efeitos sonoros relativos a guerra, como sons de batalhas, tiros e explosões. ${ }^{9}$ A música foi sobreposta a atmosfera da Revolução fora do teatro, enquanto os protestos aconteciam. É interessante observar como as autoridades tentavam cegar a multidão com gás lacrimogênio ao mesmo tempo que os artistas de teatroBaccar e Jaïbi- tentavam, através da história de Yahia, abrir os olhos do público e revelar o despotismo do governo tunisiano.

As apresentações dessa peça durante a Revolução, quando o palco reflete as ruas e vice-versa, nos oferece a oportunidade de sair do teatro e ir para as ruas, que ${ }^{9}$ Para outros detalhes, assista ao vídeo Extraits de Répétitions de Amnesia (Ensaios da peça Amnésia) no seguinte site: <http://www.theatrecontemporain.net/
spectacles/Amnesia/extraits/idcontent/25004>. 
nessa situação, como é o caso em momentos revolucionários, se tornam metafórica e algumas vezes realmente um palco em si mesmas. Em nossos tempos, essa dinâmica foi ampliada devido à facilidade de acesso a aparelhos de gravação em vídeo e à rápida circulação das imagens obtidas. Assim que a notícias do voo de Ben Ali circularam em Tunis, um tunisiano, Abd-En-Nasser Laouini, expressou sua alegria, compartilhada com a maioria de seus compatriotas, saindo à rua principal de Tunis, a Avenida Habib Bourguiba, em um gesto espontâneo não muito diferente a um monólogo teatral. Como a avenida estava quase deserta, devido a um toque de recolher imposto durante a revolução, Laouini parecia estar sozinho a celebrar o fato de que Ben Ali havia partido. O cenário, a rua, se tornou um palco virtual. $\mathrm{O}$ vídeo ${ }^{10}$, feito, sem que Laouini percebesse, por observadores no apartamento de frente para a rua, revela a excitação de Laouini pelo futuro dos tunisianos sem Ben ali, e também sua fúria contra os obscuros anos de uma liderança opressiva. As palavras de Laouini são poderosas, dramaticamente falando:

Ben Ali fugiu/ Não mais medo/ Levantem suas cabeças/ Nós estamos livres/ O povo tunisiano está livre/ O povo tunisiano não morre/ Os tunisianos são fantásticos/ Vida longa a uma Tunísia livre/ Glória aos mártires/ Liberdade aos tunisianos/ Ó vocês, tunisianos que estão exilados/ Ó vocês, tunisianos que estão presos/ Ó vocês, tunisianos que sofreram/ Ó vocês, tunisianos que foram oprimidos/ Ó vocês, tunisianos que foram injustiçados/ Ó vocês, tunisianos que foram roubados/ Respirem liberdade/ O povo tunisiano oferece liberdade a todos nós/Vida longa ao povo tunisiano/ Vida longa à grande Tunísia/ Vida longa e liberta/ Glória aos mártires/ Ó, tunisianos, chega de medo/ $\mathrm{O}$ criminoso fugiu/ $\mathrm{O}$ criminoso fugiu/ Ben ali fugiu/ Ben Ali fugiu do povo tunisiano/ Ben Ali fugiu ( $5 \mathrm{x}$ vezes)/ $\mathrm{O}$ criminosos fugiu/ $\mathrm{O}$ ladrão fugiu/ $\mathrm{O}$ boca impiedosa fugiu/ fugiu, fugiu para Líbia/ E agora o povo governa/ [...]/ você sacrificou o que não tem preço/ Ó nosso povo, você sacrificou nossas crianças. (Laouini, 2011)

Além do óbvio fato de que a mensagem de Laouini seja política, ela é também fortemente teatral, seguindo a forma de um inusual monólogo, mesmo que o orador não tivesse intenção alguma de endereçá-lo a um público. O próprio Laouini não sabia que havia sido filmado, até o vídeo ser repetitivamente transmitido tanto nos canais de TV nacionais e internacionais, quanto pelas redes sociais como Facebook, Twitter e YouTube. No entanto, sua "performance" foi analisada não só em termos linguísticos, mas como um desafio às restrições impostas pelas autoridades tunisianas. Além de infringir a lei por estar na rua depois do toque de recolher, os movimentos de Laouini cruzando a avenida foram acompanhados pelo seu apelo entusiástico para que os tunisianos despertassem, suas mãos subiam e desciam como se quisesse despertar a consciência de todos, alertando-os a lembrar a história política da Tunísia, condensada na apresentação de seu monólogo. O levante na Tunísia foi, em larga escala, moldado por performances da vida real. $O$ vídeo de Laouini representa um momento político que se tornou uma realidade teatral em virtude de ter sido filmado. $O$ vídeo ilustra como a realidade se torna teatral através não só da expressão de ideias, mas da realização delas.

Assim, a preocupação com a proximidade entre arte e vida ilumina a leitura de

${ }^{10}$ É possivel visualizar o no seguinte endereço: < https://www.youtube.com/watch?v=TNzC401Qh1c>. (N.T.). 
Khamsūn (Cinquenta), Yahia Yaïsh (Amnésia), assim como também a da criação e circulação do vídeo ("Ben Ali Fugiu! "). Os acontecimentos de Khamsūn preenchem as lacunas faltantes na política tunisiana, como a pluralidade política, e corretamente preveem que grupos de minoria extremista poderiam surgir após um longo período de repressão política. Yahia Yaïsh não apenas apresenta a figura de um governante que comete abuso de poder, mas também anuncia sua iminente queda, seguida pela fuga da condenação da justiça, extraordinariamente prevendo os eventos da vida real que logo seriam materializados durante a revolução tunisiana. "Ben Ali Fugiu! " marcou um momento político da Tunísia e enfatizou, de maneira bem diferente, a proximidade entre as performances teatrais e sociais.

Depois da revolução podemos ver claramente como Khamsūn abordou a real incompetência política na Tunísia e como Yahia Yaïsh igualmente representou e previu a queda do regime tunisiano. Desde a revolução, o governo tunisiano tem permitido a criação e a participação de vários partidos políticos. Ainda assim, o governo não é capaz de gerir eficazmente os desafios da pluralidade. Devemos esperar que performers inspirados e criativos, nos teatros e, talvez, nas ruas também, apresentem os modelos necessários para o desenvolvimento de uma sociedade civil de fato, em nome da qual a Revolução foi iniciada.

\section{Referências}

AMINE, Khalid; CARLSON, Marvin. Post Colonial Theatre in the Maghreb. In The Theatres of Morocco, Algeria, and Tunisia: Performance Traditions of the Maghreb. Nova lorque: Palgrave Macmillan, 2012.

BACCAR, Jalila. Khamsūn. Tunis: Dār al-Janūb, 2007.

BACCAR, Jalila; JAÏBI, Fadhel. Yahia Yaïsh. [S.L.:s.n.], 2010.

BACCAR, Jalila ; JAÏBI, Fadhel. Grand entretien avec Fadhel Jaïbi et Jalila Baccar. France Culture, França, 24 jan. 2011. Entrevista concedida a Caroline Broué e Hervé Gardette.

BOUTEILLET, Maia. L'Odéon, Porte de Sortie pour Corps Otages. Libération, Paris, 20 mai. 2007. Disponível em: < http://www.familiaprod.com/presseliberation.htm>. Acesso em: 10 ago. 2011.

DALEY, Suzanne. Tensions on a Campus Mirror Turbulance in a New Tunisia. New York Times, Nova lorque, 12 jun. 2012.

JORSHI, As-Salafyya fi Tunis bayn Qam' as-Sulta wa Makhawif an-Nukhba. In Min qabdat Bin 'Ali ila thawrat al-Yãsamīn: al -islām al - siyāsī fî Tūnus. [S.L.:s.n.], 2011.

LAMAZOU, Zoé. Pièce Explosive à Tunis. Jeune Afrique. Abril, 2007. Disponível em $:<$ http://www.familiaprod.com/presselintelligent.htm>. 
LAOUINI, Abd-En-Nasser. Al-Mashhad al-ladhi-Abkāni wa Abkā Rached Ghanouchi. Disponível em< http://www.youtube.com/watch?v=kDhnM0_Z54Q\&feature=related>. Acesso em: 17 jan. 2011.

QUIROT, Odile. La Révolution Tunisienne Sur Scène: La Chute du Tyran. Le Nouvel Observateur. Paris, jun. 2011, p. 80.

TALBI, Mohamed. Goulag \& Démocratie. Tunis: Finzi, 2011.

Recebido em: 30/01/2016

Aprovado em: 05/02/2016 